\title{
Epidemiological and surgical aspects of brain trauma injury of the child: Experience of the Gabriel Toure University Hospital Center, Bamako, Mali
}

\author{
Moussa Diallo ${ }^{1 *}$, Mohameth Faye $^{2}$, Mohamed A Cissé ${ }^{2}$, Youssouf Sogoba ${ }^{1}$, Diango Djibo $^{3}$ and Drissa Kanikomo $^{1}$ \\ ${ }^{1}$ Department of Neurosurgery, CHU Gabriel TOURE Hospital Center, Bamako, Mali \\ ${ }^{2}$ Department of Neurosurgery, CHU Fann Hospital Center, Dakar, Senegal \\ ${ }^{3}$ Department of Emergency Medicine, CHU Gabriel TOURE Hospital Center, Bamako, Mali
}

\begin{abstract}
Introduction: Cranial trauma represent the third cause of death in paediatric population in Africa. The two-wheel motor bikes proliferation in our capital cities, this tends to become a major public health problem. Very little studies concern surgical aspect of cranial trauma in children. Our purpose was to report our experience in the surgical management of traumatic brain injury in children. Furthermore, this study will help as a framework in the future for all work on the subject.

Patients and methods: It was a retrospective study for a period of 36 months (January 2014 to December 2016) conducted in Gabriel Toure Teaching hospital. It was concerning patients between 0 to 15 years old, operated in emergency of traumatic brain injury.

Results: Thirty-seven cases were collected. Majority of patients was male with an average age of 7.9 years. Traffic accidents was the principal cause. At their admission in emergency department, $27 \%$ was in coma, $24.3 \%$ was presenting neurologic deficit. Extra dural hematoma (EDH) was diagnosed in $40.6 \%$ of our patients, followed by depressed skull fractures. Average surgical delay was of 1.7 day. The average length of the surgery was 2 hours and 5 minutes. Two cases of cerebral abscess were recorded. Evolution was favourable in $24.3 \%$ cases with $13.5 \%$ of death. Seventy-five patients had presented favourable evolution.
\end{abstract}

Conclusion: Children's traumatic brain injury management is complex with random results when it's done out of a paediatric neurosurgical unit. The lack of suitable equipment, delay in management and long surgical procedure contribute to bad therapeutic results.

\section{Introduction}

Cranial trauma is the third cause of child mortality in the world, particularly in Africa after perinatal diseases and infections [1]. Trauma and Violence are causes for more than 950000 children's and young people's deaths around the world. Among these trauma, Traumatic brain injuries (TBI) have a special place. Children's traumatic brain injuries constitute a major public health problem due to their frequency, their gravity and their costs [2]. Besides their mortality, they often are responsible of severe disabilities with considerable socio-economic consequences. TBI management present a real problem in country with impoverished neurosurgical environment in suitable equipment for children.

This work aimed to highlight epidemiologic characteristics of cranial trauma in Mali, report our experience in TBI surgical management and finally identify problems related to children's TBI surgery in Gabriel Touré university hospital center of Bamako.

\section{Patients \& methods}

It was a retrospective study of 36 months between January 2014 and December 2016, conducted in Neurosurgery Unit of Gabriel TOURE hospital center of Bamako in Mali.

All patients of both sexes, aged from 0 to 15 years, admitted in accident and emergency department and surgically managed for TBI the 5 next days following their admission were include in the study.
Presence of TBI's clinical signs and their confirmation by cerebral CTScan justifying surgery was part of criteria.

Patients over 15 years, those who didn't realize diagnostic cerebral CT-Scan, children suffering of TBI who didn't have surgery or who had it more than 5 day after their admission was excluded.

The studied parameters were age, sex, trauma mechanism, clinical and radiologic presentation and evolution. The data was reported on an Excel $^{\oplus}$ sheet and analyzed with Stata 11 software.

\section{Results}

One hundred forty-six patient aged from 0 to 15 years, was suffering of TBI between January and December 2016 of whom 37 was surgically managed $(25.34 \%)$. The average age was 7.9 years with a high rate in $11-$ 15 years group (Figure 1). This condition was concerning male in $56.8 \%$ cases. $37.8 \%$ of these children was not attending school. Traffic accidents was TBI principal cause with $46 \%$ of cases followed by home accidents

${ }^{\star}$ Correspondence to: Moussa DIALLO, 1Department of Neurosurgery, CHU Gabriel TOURE Hospital Center, Bamako, Mali, Tel: (+223) 998787 03; E-mail: mdiallo5@gmail.com; moussa.diallo@fmos.usttb.edu.ml

Key words: child, craniectomy, intracranial hematoma, surgery, trauma brain injury

Received: April 01, 2019; Accepted: April 10, 2019; Published: April 15, 2019 


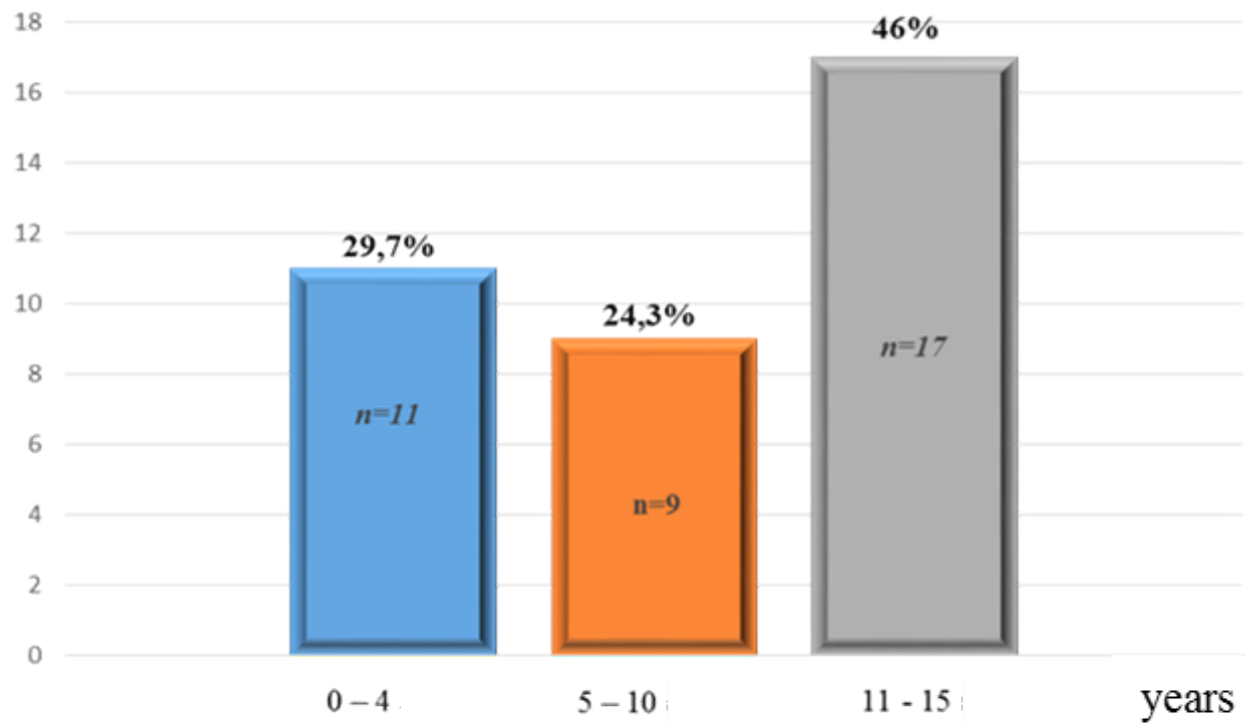

Figure 1. Patients repartition by age

(32.4\%) and assault and battery (21.6\%); no case of abuse was reported. Home accidents was dominated fall from heights. Among those 146 children suffering of cranial trauma, $24 \%$ was brought by firemen, the other $76 \%$ was brought to hospital by not medicalized ways ( $43 \%$ by personal car and $33 \%$ by taxi). Table 1 summarize patients' Glasgow Coma Scale (GCS) Score at their admission in emergency. Ten patients were in comatose state; nine patients were presenting a neurologic deficit on headaches ground. $48.7 \%$ of patients (18 cases) presenting headaches with unrest. In this headache (cephalalgic) group, 9 had presented a secondary degradation made of consciousness disorders (06 cases), hemiparesis (03 cases), and unrest persistence in 3 children.

At cerebral CT-scan, extra-dural hematoma (Image1-C) was the most seen followed by depressed skull fractures (Image1-A), onset acute subdural hematoma (Image 1-B) and finally intracranial hypertension caused by cerebral oedema (Image1-D) with respectively $21.6 \%, 16.3 \%$, $13.5 \%$ and $8.1 \% .40 .5 \%$ of children was suffering of associated injuries; they was distributed between maxillofacial injuries (16.2\%) and limbs trauma (24.3\%). In this latter group it's noted lower limb fractures (66.7\%) and 3 cases of upper limb fractures (33\%).

The average delay between admission in emergency and surgery (Figure 2) was 1.7 day (40.8 hours) with range of 4 hours to 5 days. Only four patients had surgery on the first 8 hours after their admission. The main surgical technique adopted was craniectomy with or without bone flap replacement (Table 2). Average length of the surgical procedure was 125 minutes with rates from 102 to 200 minutes. For the eight patients who had a decompressive craniectomy, the bone flap was replaced for two patients two months after surgery and for the others six between four and seven months after surgery. A craniectomy without bone replacement was made for two patients of seven and 14 years old and the cranioplasty is still not realized.

The 15 cases of extradural hematoma surgery had consisted of hematoma evacuation, bleeding vessels haemostasis, dura mater suspension and finally bone flap replacement (Image 2). Bone flap wasn't immediately replaced for four patients. Per-operatory observations showed origin of the bleeding which caused the extradural hematoma was in $73.3 \%$ ( 11 patients) from the middle meningeal artery and from skull fracture in $26.7 \%$ (four patients).

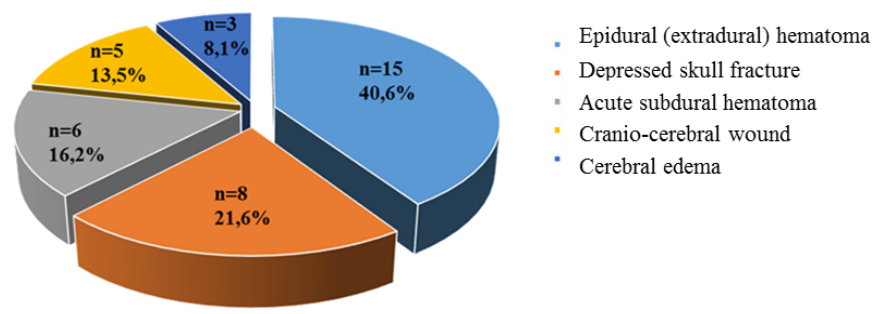

Figure 2. Patients repartition by surgical pathology on CT-scan
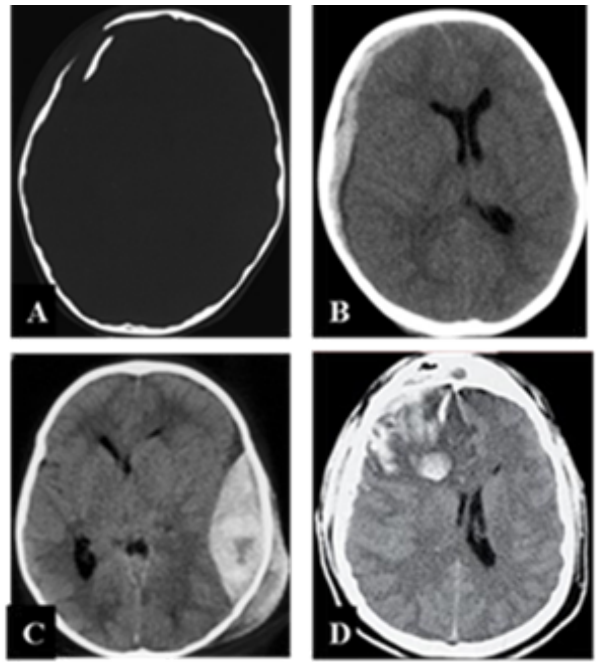

Image 1. Diagnostic brain CT-scan

Table 1. Patients repartition by Glasgow Coma Scale at admission

\begin{tabular}{|c|c|c|}
\hline Glasgow Score & Effective & Rate $\%$ \\
\hline 15 & 17 & 46 \\
\hline $13-14$ & 4 & 10,8 \\
\hline $9-12$ & 6 & 16,2 \\
\hline Total & 10 & 27 \\
\hline
\end{tabular}

Twenty-seven of our patients was in comatose state at their arrival in emergency 
Table 2. Repartition of TBI by used surgery technique

\begin{tabular}{|c|c|c|c|c|c|}
\hline Diagnosis & Effective & Rate (\%) & \multicolumn{2}{|c|}{ Surgery technique } & Effective \\
\hline \multirow[b]{2}{*}{ EDH } & \multirow[b]{2}{*}{15} & \multirow[b]{2}{*}{40,6} & \multirow{3}{*}{$\begin{array}{l}\text {-Craniectomy } \\
\text {-EDH Evacuation } \\
\text {-Epidural Suspension }\end{array}$} & No bone replacement & 4 \\
\hline & & & & bone flap replacement & 11 \\
\hline Depressed & & & \multirow{2}{*}{\multicolumn{2}{|c|}{ Decompressive surgery }} & \\
\hline $\begin{array}{l}\text { Skull } \\
\text { Fractures }\end{array}$ & 8 & 21,6 & & & 8 \\
\hline \multirow{3}{*}{ Onset sub dural hematoma } & \multirow{3}{*}{6} & \multirow{3}{*}{16,2} & \multirow{2}{*}{-Craniectomy } & No bone replacement & 1 \\
\hline & & & & bone flap replacement & 5 \\
\hline & & & \multicolumn{2}{|c|}{-Dura-mater Plasty } & \\
\hline \multirow{3}{*}{ Cranio-cerebral wounds } & \multirow{3}{*}{5} & \multirow{3}{*}{13,5} & \multirow{2}{*}{-Craniectomy } & No bone falp & 2 \\
\hline & & & & Bone flap replacement & 3 \\
\hline & & & \multicolumn{2}{|c|}{$\begin{array}{l}\text {-Parage } \\
\text { - Dura-mater Plasty }\end{array}$} & \\
\hline $\begin{array}{l}\text { Cérébral } \\
\text { swelling }\end{array}$ & 3 & 8,1 & \multicolumn{2}{|c|}{ Decompressive craniectomy } & 3 \\
\hline Total & 37 & 10 & & & 37 \\
\hline
\end{tabular}

Craniectomy was the most used surgery technique with immediate bone flap replacement in $65.5 \%$.
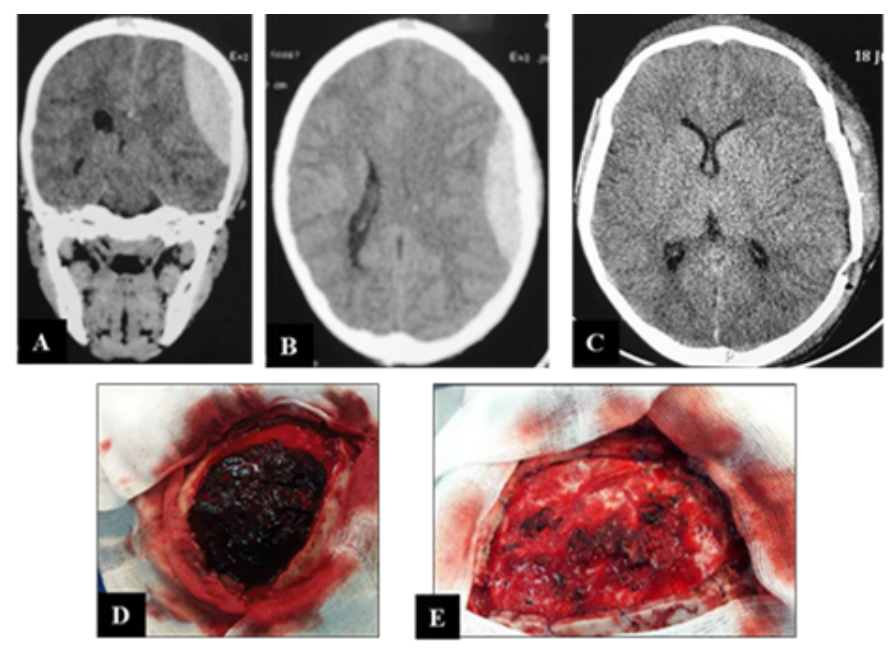

Image 2. Extradural hematoma

The five cases of craniocerebral wounds were treated by surgical debridement through a craniectomy followed by duraplasty by scalp. Two of them had craniectomy without replacement.

Evolutionary, only $54.1 \%$ of patients could realize postoperatory control CT-Scan. Post operatory evolution was marked by complications which occurs in $8.1 \%$ of cases divided between a cerebral abscess ( 2 cases) and binocular blindness ( 1 case). Average hospital stay was 19 days with range from 13 to 32 days. Average follow up delay was 18 months (range of 6 to 31 months). Three patients had residual neurologic deficit. Mortality rate of $13.5 \%$ was recorded during the study. Among the 5 cases of death, 3 was related to pneumonitis, 1 to anaemia and 1 to cardio respiratory arrest. The evolution overall was favourable with $86.5 \%$ of cases, of which it was good in $78.4 \%$ and average in $8.1 \%$ ( 3 cases of neurological deficit in recovery)

\section{Discussion}

Cranial trauma incidence in children vary from study and constantly increasing. The real incidence of this condition in general paediatric group it's unknown because lot of studies as our one is based on hospital records which don't consider prehospital death and abuse children. Moderate and severe trauma was representing $46.1 \%$ of TBI in Cotonou in 2014 [3]. Almost half million of the 1.7 million American's civils who was suffering of cranial trauma was aged of 14 years or younger [4]. Cranial trauma is the third cause of child mortality around the world particularly in developing countries after perinatal diseases and infections [1]. In Mali, fight against infectious diseases is the main public health policy preoccupation which tend to minimize cranial trauma consequences especially in children.

Annual incidence of TBI in children in our study was 48.6 cases by year. Male dominance was found in our study as reported in literature with variable rate (2.3 and 5). Sex ratio of TBI increase with age [5] and is multifactorial. In our study, we found that mechanisms of head trauma are age-dependent. In the youngest (infants), these are accidents that have been characterized by decreases. Some authors have said that this mechanism is the leading cause of TBI in paediatric settings [6-9]. In our country, road accidents mainly concern children of two age groups. The 0 to 4 age bracket refers to children who are carried on the backs of their mothers or unmasked passengers on a motorcycle at the time of the crash causing head trauma. From 11 to 15, in Mali, children start driving motorcycles as early as 11 years old most often. Ignorance or non-compliance with the highway code at this age associated with the lack of helmets exposes them to a serious TBI. -

Clinical picture is highly variable in young age children suffering of TBI [10]. Skull extensibility, ventricular and peri-cerebral fluid sector presence allow a better tolerance to high intracranial hypertension firstly. This misleading sign made of headaches healed by usual antalgics had concerned $48.7 \%$ of our patients. Face to this presentation said "minor", no cerebral exploration was realized in first intention in these patients. Secondarily, half of those children have presented severe neurologic signs which conduct them to a surgical management. This bring us to the issue of CT-Scan realization in paucisymptomatic children suffering of TBI.

For comatose patients and these which have a focal neurologic deficit, the clinical exam have to be summarized and, in any circumstances, can't delay cerebral imagery which is necessary. Cerebral CT-Scan is the helping imaging in first intention because of its accessibility and his fast realization. It allows in absence of surgical brain injuries to influence the therapeutic management. Body scan realization can be an interesting option in most of the case of children's cranial trauma in the way that in our context most of the time they are related to traffic accidents with high kinetics plus high possibility of associated extra cranial injuries. But this option is limited in one hand by financial accessibility in Mali 
as in all developing countries, a few people have a health insurance and in other hand by lack of consensus on this practice on children due to the X-Ray exposition risk. This Imaging is an effective and fast diagnostic way of cerebral injuries and associated injuries on which can depend the prognosis. In their study Mendy and al had found $61.6 \%$ of associated extra brain injuries [6] against $40.5 \%$ in our series with a high predominance of limbs fractures. This difference of associated injuries frequency in those 2 studies could be explained by enrolment's criteria. The search of abdominal and thoracic trauma injuries was oriented by clinical examination and if needed by Chest X-Ray and abdominal ultrasound.

Extra-dural hematoma (EDH) was the most common intracranial injury in our series (Figure 3). This can explain the violent character of the trauma which was related in majority to traffic accidents. EDH with cerebral haemorrhagic contusion was the most common endocranial injuries found in Hode's series at Cotonou in Benin [3]. In some studies, cerebral contusion was the most common traumatic brain injuries found with respectively $25.8 \%$ [6] and $41 \%$ [9]. Particular physiology of children's brain can explain some injuries predominance particularly reactive brain swelling [6].

Our study had concerned children operated of traumatic brain injuries in the 5 days following their admission to hospital. Children's head injury surgically managed frequency varies from one study to another. Maghreb countries present a higher frequency of children surgically managed in emergency for traumatic brain injuries between $13 \%$ [2] and 40\% [10] against West Africa's countries between 11 [3] and $15.17 \%$ [6]. This disparity could be explained by developing health system in Maghreb countries where neurosurgery was practiced for decades, plus a significantly lower ratio of neurosurgeon/population in the Sub Saharan countries. Mali numbered twelves neurosurgeons for a population of almost 18 million people. Due to countries socioeconomic situation hospital is not the first destination for children suffering of TBI especially if he doesn't present neurological disorders.

Sometimes they are received in surrounding health structure where lack of qualified staff is crucial; otherwise they are brought back to home for auto medication instituted by the parents. In case of unfavourable evolution, traditional healer competences are first required before hospital for these who still been lucky to reach it. Since several years, a massive awareness campaign was established in hospitals and nonhospital community by community radio and in school forming sanitary agents to refer directly children suffering of TBI to Gabriel Toure Teaching hospital regardless of their clinical state. Although the 146 children who was suffering of TBI received in Gabriel Toure teaching hospital emergencies allow us to hope, further efforts were still required at lot of stage to reach changes in empirical habits.

Surgery had consisted to craniectomy with or without bone replacement. Difficulty to realize this technic was logistical due to condition of equipment or lack of equipment essential to this surgery. Craniectomy was made sometimes by a rongeur or Kerisson rongeur due to high speed electric drill unavailability. The first one leaves a post operatory cranial dysmorphia and the second one increase the risk of complication by lengthening the surgery and important bleeding. The delay to replace the bone flap for children who had a decompressive craniectomy was related to financial issues or lack of medical aid. Acrylic cement cranioplasty wasn't realized on children who had craniectomy without bone flap replacement because our inexperience in this practice on children. We think the fact the children are growing, and prosthetic implant placement could have consequences in long term.
Despite a favourable evolution for the majority of our patients, a mortality rate of $13.5 \%$ was recorded. It was concerned with young children and was mostly related to secondary brain damage and decubitus complications. Mendy \& $\mathrm{Al}$ in their series found a mortality rate of $34.8 \%$ with $32.42 \%$ of neurologic sequelae [6]. According to them, major causes of deaths and disabilities were related to cerebral hypoxia [6]. It was reported by some authors that children under 2 years have a higher risk to develop complications during their traumatic brain injuries management [11]. Some factors have been described as of bad prognosis in presence of post trauma intracranial hematomas in children [11]. These includes low Glasgow coma scale score, high post operatory intracranial pressure, long interval between trauma and surgery, long duration of cerebral hernia, per operatory presence of cerebral swelling, bulk and thick hematomas and mass effect on median structures and finally obliteration of basal cisterns [12]. According to Amsaga \& Al, bradypnea, tachycardia, hypotension, dyscoria, GCS score lower or equal to 12 , retinae haemorrhage, subdural hematoma and brain swelling are associated to mediocre neurologic results $(P<$ $0,05)$ [13]. Secondary cerebral injuries which can distort neurologic results can be preventing by early surgeries [13].

However, the big cerebral compliance due to incomplete skull sutures ossification, and neuroplasticity concept could explain at least partly, children's higher post trauma neurologic recovery abilities. Even it's clear that emergency handling reduces neurologic complications, really there is no clarified delay for surgery; limits are established by patient clinical condition. Children are growing organisms, so they have high potential for recovery. In our study, $86.5 \%$ of patients operated on within 5 days of their trauma presented a favourable evolution. This was a function of their age, the severity of their lesions, and their initial clinical states.

\section{Conclusion}

The management of head trauma in children is really complex with random results if performed outside a neurosurgery unit. The lack of appropriate devices and the delay in the management contribute to the poor therapeutic results. The result of the clinical and radiological data must be taken into account for the surgical indication in order to prioritize the acts. The evolution is generally unfavourable for the very young children with important intracranial lesions

\section{Conflict of interest}

We declare no conflict of interest

\section{References}

1. Peden M, Oyegbite K, Ozanne-smith J, et al. Rapport mondial sur la prévention des traumatismes chez l'enfant. Genève, Organisation mondiale de la Santé et UNICEF, 2008.

2. Mentri N, Izirouel K, Himeur H, Takbou I, Tliba S (2018) Les traumatismes crâniens lors des accidents domestiques chez l'enfant. Neurochirurgie 64: 272-273.

3. Hode L, Sogbo DHO, Hounnou MG, Houessou GF, Voyeme AKA, et al. (2014) Prise en charge des traumatismes crânio-encéphaliques chez les enfants à Cotonou. Neurochirurgie 60: 336 .

4. Centers for Disease Control and Prevention TBI data and statistics. 2014 Available from http://www.cdc.gov/traumaticbraininjury/data/index.html.

5. Mabrouk B, Hedi C, Riadh G, Hassan D, Hatem K, et al. (2009) Traumatismes crâniens chez l'enfant dans le sud tunisien profil épidémiologique, manifestations cliniques et évolution. A propos de 454 cas Rev. Tunisie Medicale 87: 28-37.

6. Mendy J, Kpelao E, Sakho Y, Gaye M, Ndoye N, et al. (2014) Traumatismes crâniens graves de l'enfant : prise en charge et pronostic à court terme à Dakar (Sénégal). RAMUR Tome 19

7. Osmond MH, Klassen TP, Wells GA, Correll R, Jarvis A, et al. (2010) CATCH: A clinical decision rule for the use of computed tomography in children with minor head injury. CMAJ 182: 341-348. [Crossref] 
8. Popernack ML, Gray N, Reuter-Rice K (2015) Moderate-to-Severe Traumatic Brain Injury in Children: Complications and Rehabilitation Strategies. J Pediatr Health Care 29: e1-e7. [Crossref]

9. Toure MH, Diop AD, Ly M, Kikwaka JK, Dème H, et al. (2017) Traumatisme cranioencéphalique (TCE) de l'enfant: aspects tomodensitométriques à propos de 298 cas au CHNU FANN (Dakar). J Afr Imag Méd 9: 140-147.

10. Kenaan A, Karim R, Haissam M, Manfalouti M, Bertal A, et al. (2011) Les traumatismes crâniens chez l'enfant : à propos de 490 cas. Neurochirurgie 57: 300-301.
11. Schutzman S, Barnes P, Duhaime AC, Greenes D, Homer C, et al. (2001) Evaluation and management of children younger than two years old wihn apparently minor head trauma: proposed guidelines. Pediatrics 107: 983-93. [Crossref]

12. Gürer B, Kertmen H, Yilmaz ER, Sekerci Z (2013) The Surgical Outcome of Traumatic Extra-Axial Hematomas Causing Brain Herniation in children. Pediatr Neurosurg 49: 215-222. [Crossref]

13. Amagasa S, Tsuji S, Matsui H, Uematsu S, Moriya T, et al. (2018) Prognostic factors of acute neurological outcomes in infants with traumatic brain injury. Childs Nerv Syst 34 673-680. [Crossref]

Copyright: (C2019 Diallo M. This is an open-access article distributed under the terms of the Creative Commons Attribution License, which permits unrestricted use, distribution, and reproduction in any medium, provided the original author and source are credited. 